Mandatory rules not yet to be abandoned

Washington

Bending to political realities, the Recombinant DNA Advisory Committee (RAC) to the US National Institutes of Health (NIH) has backed away from its support for a proposal that guidelines covering NIH-sponsored research using recombinant DNA techniques should be made voluntary, and that research institutions should no longer be formally required to establish safety committees to ensure that the guidelines are observed.

At its last meeting in September, the members of RAC decided to support the publication for public comment of the proposals for major revisions to the guidelines that would essentially transform them into a voluntary code of conduct.

However, in the light of the comments received - and in particular of warnings that if the guidelines become voluntary states such as California are likely to introduce their own more restrictive regulations - RAC on Monday adopted a compromise formula that would streamline the containment requirements for different types of experiments, but retain their mandatory aspects. Two proposals had been put out for comment. One, a revision of amendments originally proposed by Dr Alan Campbell of Stanford University and Dr David Baltimore of Massachusetts Institute of Technology, would eliminate all the mandatory requirements of the guidelines, including the sanction that noncompliance could lead to a loss of NIH funds.

The alternative proposal, submitted by RAC-member Dr Susan Gottesman of the National Cancer Institute, would retain the guidelines as a required procedure for those receiving NIH grants, including the requirement that certain experiments be reviewed either by $\mathrm{RAC}$ or by local Institutional Biosafety Committees (IBCs). The containment classifications, however, would be reorganized, and containment requirements for some classes of experiments would be made less stringent.

The potential consequence of transforming the guidelines into a code of practice for community opinion at local and state levels dominated the discussions.

Most informed scientists who had sent in written comments expressed strong support for making guidelines voluntary, arguing that risks once thought plausible had now been shown to be either remote or non-existent. Dr Paul Berg of Stanford
University, for example, one of the three signatories of the original letter suggesting a moratorium on rDNA research, wrote that he believed the guidelines "are now dispensable"'.

The institutional response, however, has been different. Many local IBCs, those in universities and in private industry, told $\mathrm{NIH}$ that they were not experiencing major difficulties in implementing the guidelines as they now stood. Several warned that the absence of mandatory federal guidelines would provide an opportunity for the introduction of a patchwork of individual laws.

The Industrial Biotechnology Association, for example, which represents a number of small biotechnology companies such as Cetus and Genex, wrote that "one significant reason for adherence to a uniform system of federal guidance and overseeing is our belief that such an approach is more compatible with commercial development and the benefits it brings to society than would be a system of varying local requirements".

If there was an unexpected consensus at Monday's meeting that a strong federal presence in regulating rDNA research remains desirable, there was less agreement on whether the potential hazards of such research should be treated differently from related areas of biomedical research.

Some members of the committee, arguing the lack of substantial evidence of additional hazard, suggested that this was a reason for adopting uniform practices by making guidelines voluntary. Others, however, used the same data to urge that the experience of RAC should be used as a basis for encouraging a similar approach to research with other organisms.

After hearing the arguments for both proposed revisions, the members of the committee voted by 17 to 3 to adopt those put forwards by Dr Gottesman as the basis for revising the guidelines, rather than those which had been informally endorsed at the September meeting. It also agreed to set up a small working group to revise the specific recommendations which she had put forward to change the current classifications, and to present its conclusions to the director of the National Institute for Allergic and Infectious Diseases, Dr Richard Krause, who will decide what changes to the guidelines will be introduced.

\title{
Budget protection for research
}

\section{Washington}

The United States scientific community has done relatively well out of the budget proposals which President Ronald Reagan submitted to Congress on Monday for the fiscal year 1983, which begins on 1 October.

Overall, the President is requesting an increase of about 10 per cent in expenditure on research and development. With an officially-estimated inflation rate of 6.5 per cent, the Administration is claiming that this would represent a real growth in research and development of about 3.5 per cent. The same pattern of growth is being suggested for the basic research budget, scheduled to increase by 8.8 per cent to a total of $\$ 5,821$ million.
In both instances, the major contribution to this growth has been increased spending on military research, which rose 25 per cent between 1981 and 1982, and is scheduled for a further growth of 18.9 per cent next year.

Where these increases reflect $\mathrm{Mr}$ Reagan's election campaign promises to boost United States military strength, another promise is reflected in moves to reduce substantially federal sponsorship of energy research, on the grounds that this should, where possible, be made the responsibility of the private sector.

The most dramatic reductions are proposed in solar research and other renewable energy sources, such as hydropower and geothermal, scheduled to come

Recommended budget obligations for fiscal year 1983

\begin{tabular}{cccc} 
Research and development & \multicolumn{2}{c}{ Basic research } \\
Total & Increase & Total & Increase \\
(million \$) & $1982-83(\%)$ & (million \$) & $1982-83(\%)$
\end{tabular}

Department of Defense

Space Administration

Energy Research and Technology Administration*

National Institutes of Health

National Science Foundation

US Department of Agriculture

Environmental Protection Agency

Other agencies

Total
National Aeronautics and

$\begin{array}{rrrr}24,469 & 18.9 & 781 & 16.0 \\ 6,513 & 12.1 & 682 & 17.6 \\ 3,917 & -13.3 & 741 & 14.5 \\ 3,533 & 3.1 & 1,897 & 3.1 \\ 1,033 & 7.5 & 984 & 7.9 \\ 838 & 3.8 & 359 & 8.1 \\ 230 & -27.4 & 10 & -50.0 \\ 2,464 & & 367 & \\ 42,997 & 10.7 & 5,821 & 8.81\end{array}$

*Previously Department of Energy, intended to become part of the Department of Commerce. 
down from $\$ 248$ million in 1982 to $\$ 83$ million in 1983. Energy conservation research would be reduced even more drastically, from $\$ 144$ million to $\$ 18$ million; both proposed cuts are expected to be challenged in Congress.

Another agency which has been the target of criticism from the private sector and which would also see its research budget cut under Mr Reagan's 1983 proposals is the Environmental Protection Agency, down from $\$ 317$ million to $\$ 230$ million.

Other research agencies, however, have done quite well, reflecting a broadly-based acceptance within the Administration that strong federal support for research and development is a legitimate claim on the public purse.

The National Science Foundation, for example, is listed for a budget increase of 7.5 per cent, with considerable real growth in areas such as computer research (up 14 per cent) to $\$ 29.3$ million, earth sciences (up 17.8 per cent) and mechanical engineering (up 13.7 per cent). The Administration has relented slightly in its efforts to cut back support for the social and economic sciences, having initially requested $\$ 10$ million in the 1982 budget, but now supporting a figure of $\$ 17.8$ million in 1983, the same level to which the 1982 budget was raised by Congress. However, it is sticking to its previous determination to eliminate virtually all science education activities sponsored by the National Science Foundation, arguing that education at the school level should remain primarily a responsibility of the states and local school boards.

The National Institutes of Health are scheduled for a modest 3.1 per cent increase in its research budget, slightly less than the anticipated rate of inflation. Unlike last year, the Administration is not seeking to eliminate institutional support for research training awards, a move which provoked a major outcry from biomedical research institutions.

Inevitably, budgetary stringencies have caused disappointments. The National Aeronautics and Space Administration, for example, has for the moment abandoned plans to send an orbiting imaging radar to Venus; but the rumoured extinction of the Galileo mission to Jupiter failed to materialize, and space science is scheduled for a healthy increase of almost 20 per cent, including full funding for the gamma-ray observatory, as well as sustained support for the space shuttle.

Dr George (Jay) Keyworth, the President's Science Advisor, said on Monday that he was "delighted" with the budget increase for science. He said that the physical sciences, once in jeopardy, had been spared during the review process to enable increased utilization of existing particle accelerators. "Next year", he said, "there will be more effort to separate the mediocre from the excellent in research."

David Dickson

\section{US budget described in outline}

\section{Energy support \\ Washington}

Not unexpectedly, the requested budget for the Energy Research and Technology Agency will contain strong support for the Clinch River liquid metal fast breeder reactor. The design and construction of the fast breeder are described as priorities and will receive $\$ 257$ million for the initiation of site preparation and continued procurement of parts.

However, work on both the Large Development Plant, started by the Carter Administration as an alternative to Clinch River, and the light water breeder reactor will be phased out, leading to an overall decrease of $\$ 108$ million from 1982 in spending on breeder reactors.

There will also be reduced support for fusion research, with the focus shifting from the construction of new facilities to what the Office of Management and Budget describes as "resolving key outstanding physics and technology issues". This will delay construction of the tandem mirror test facility at the Lawrence Livermore Laboratory, a decision which has contributed to the resignation of the head of the Department of Energy's fusion programme, Dr Edward Kintner.

Funds for inertial confinement fusion, until recently treated as a major alternative to the magnetic fusion programme, have also been reduced from $\$ 209$ million in 1982 to $\$ 119$ million in 1983 , again through shifting the focus from the completion of new facilities, such as Lawrence Livermore's Nova device, towards experiments on existing machines.

In contrast to the continued - if slightly reduced - support for research into nuclear fusion and fission, only $\$ 315$ million is being requested to support research in fossil, solar, biomass and other renewable energy sources, compared with $\$ 814$ million in 1982 .

\section{Unrest on loans}

If US universities have been relieved at escaping the prospect of heavy cuts in research spending, there is less consolation in the Reagan Administration's proposals to limit its assistance for students by reducing the support for the Guaranteed Student Loan (GSL) programme.

First introduced in 1965, the programme provides loan guarantees and interest subsidies to states, private lending institutions and eligible students. Under the present plans, federal support would increase from $\$ 3,397$ million in 1983 to $\$ 3,768$ by 1987 . Tightening up on eligibility requirements and increasing the costs of obtaining a guaranteed loan will result in savings of $\$ 912$ million in 1983 , rising to $\$ 2,247$ million by 1987 .

Loans to about 600,000 graduate students would disappear under plans to reduce by about a third the number of so- called Pell awards. Graduate students would be restricted to raising loans from the less-heavily subsidized GSL auxiliary loan programme, and lending institutions would be required to pay a higher insurance premium to the government.

The Administration claims that the cuts are justified on the grounds that the primary beneficiaries of the guaranteed loans have been "middle and upper income families", which had as a result been able to put their own savings into investment schemes yielding far higher returns. The universities, however, are worried that tightening up the loan conditions could lead to a severe drop in student numbers.

David Dickson

\section{ISABELLE}

Construction work on ISABELLE, the $400 \times 400 \mathrm{GeV}$ proton-proton accelerator at Brookhaven National Laboratory on Long Island, New York, will be halted under budget plans for the Department of Energy for 1983. However, development work will continue as an accelerator research and development programme on superconducting magnets.

In general, high-energy physics has done well in the budget proposals. Mr Reagan is seeking an increase of 17.5 per cent in funding to $\$ 429$ million, claiming this will allow increased use of existing research facilities, the completion of both the Energy Saver and the Tevatron I and II at Fermilab, and further research and development at the linear collider being planned by Dr Burton Richter at the Stanford Linear Accelerator Center.

Construction on ISABELLE, which started in 1978 and had been due for completion in 1987, has been held up largely due to difficulties with the magnets. Although these now appear to have been solved, the delays have meant extra expense. Last November, a special panel set up by the Department of Energy's High-Energy Physics Advisory Panel to look at the future of US high-energy physics concluded that ISABELLE was still important, but did not place its completion as a first priority in stringent budget conditions.

According to the Office of Management and Budget, the accelerator research at Brookhaven will be related to a "future high-energy physics accelerator project", and "any decision to proceed with this project will be based on overall scientific potential and budget considerations".

\section{Space science}

The Venus Orbiting Imaging Radar (VOIR) has been dropped from the National Aeronautics and Space Administration (NASA)'s list of future planetary exploration missions. However, the agency is discussing with space scientists the possibility of launching a 